\title{
PENGARUH TINGKAT PENDIDIKAN DAN PENGALAMAN KERJA TERHADAP KINERJA KARYAWAN PT JASAMARGA TOLLROAD OPERATOR
}

\author{
Nia Putri Astriyani ${ }^{1}$, Andi Sessu ${ }^{2}$, Budi Permana Yusuf ${ }^{3}$ \\ ${ }^{1-3}$ Fakultas Ekonomi dan Bisnis Program Studi Manajemen Universitas Muhammadiyah \\ Prof. Dr. Hamka, Jakarta, Indonesia \\ E-mail: niaputri1697@gmail.com
}

\begin{abstract}
ABSTRAK
Pada penelitian memiliki tujuan untuk mengetahui pengaruh tingkat pendidikan dan pengalaman kerja pada kinerja karyawan PT Jasamarga Tollroad Operator.

Variabel bebas dalam penelitian ini yaitu tingkat pendidikan dan pengalaman kerja, sedangkan variabel terikat yaitu kinerja karyawan. Populasi nya yaitu seluruh karyawan PT Jasamarga Tollroad Operator sebanyak 165 orang dan diambil sampel sebanyak 117 orang. Penelitian ini memakai data primer dengan cara menyebarkan kuisioner pada responden. Tekhnik pengambilan sampel dengan teknik sampel acak. Metode analisis data yang digunakan yaitu uji validitas, uji reliabilitas, uji asumsi klasik, analisis regresi linear berganda, uji koefisien determinasi, koefisien korelasi, serta uji hipotesis.

Pada hasil penelitian menunjukan tingkat pendidikan dan pengalaman kerja memiliki pengaruh signifikan secara simultan dan parsial pada kinerja karyawan di PT Jasamarga Toollroad Operator.
\end{abstract}

Keywords : Tingkat Pendidikan;Pengalaman Kerja; Kinerja Karyawan

\section{ABSTRACT}

This study aims to determine the effect of education level and work experience on the performance of employees of PT Jasamarga Tollroad Operator.

The independent variables in this study are education level and work experience, while the dependent variable is employee performance. The population is all 165 employees of PT Jasamarga Tollroad Operator and a sample of 117 people was taken. This study uses primary data by distributing questionnaires to respondents. The sampling technique was random sampling technique. The data analysis method used is validity test, reliability test, classical assumption test, multiple linear regression analysis, determination coefficient test, correlation coefficient, and hypothesis testing.

The results showed that the level of education and work experience had a significant effect simultaneously and partially on the performance of employees at PT Jasamarga Toollroad Operator.

Keywords : Education Level; Work Experience; Employee Performance 


\section{PENDAHULUAN}

PT Jasamarga Tollroad Operator memiliki karyawan kurang lebih sebanyak 165 orang terdiri dari jajaran pimpinan hingga staf, cleaning service, dan security. Karyawan- karyawannya memiliki tingkat pendidikan dan pengalaman kerja tidak sama. Tentu bisa mempengaruhi pada proses kerja dari masing-masing individu. Pegawai yang memiliki tingkat pendidikan dan pengalaman kerja yang baik, dapat memberikan output kerja yang memuaskan bagi perusahaan. Oleh karena itu dengan banyaknya pekerjaan yang ada di kantor pusat tersebut, perusahaan harus memiliki karyawan dengan kinerja yang baik. Agar pekerjaan yang dikerjakan dapat selesai dengan efektif dan efisien. Dengan adanya kinerja yang baik, tentu akan dapat menghemat waktu pengerjaan pekerjaan tersebut, sehingga sangat efektif dan karyawan akan dapat menyelesaikan pekerjaan yang lain dengan cepat juga. Dalam sebuah perusahaan, setiap hasil proses tersebut akan dilakukan evaluasi atau penilaian kinerja oleh pimpinan perusahaan. Semakin baik kinerja karyawan dalam perusahaan, maka karyawan tersebut akan mendapatkan penghargaan atau reward atas kinerja mereka. Namun jika kinerja mereka turun atau kurang baik, maka biasanya perusahaan akan memberikan teguran atau dapat berupa surat peringatan atas kinerja mereka yang buruk dan tidak dapat membuat perusahaan puas. Kinerja karyawan yang baik, tentu tidak hanya memiliki dampak bagi karyawan itu saja. Selain itu, kinerja karyawan yang baik juga akan memberikan dampak atau pengaruh positif terhadap karyawan. Jika karyawan memiliki kinerja yang baik, maka perusahaan akan cepat dalam mencapai tujuan perusahaan yang telah di tetapkan.

\section{TINJAUAN PUSTAKA \\ Tingkat Pendidikan}

Soekidjo Notoatmojo (2015), mengemukakan pendidikan dalam sebuah kelompok merupakan proses perkembangan skill menuju arah yang ditujukan oleh kelompok tersebut. Menurut Andrew (2003), mengemukakan bahwa tingkat pendidikan merupakan progress dalam waktu yang lama dan memakai prosedur secara terstruktur, dimana tenaga kerja menelaah pengetahuan secara konseptual demi tercapai tujuan bersama. Menurut Azyumardi Azra (2003), mengemukakan tingkat pendidikan adalah sebuah usaha seseorang untuk menjadikan kemampuan dan perilaku, untuk kehidupan saat ini maupun kehidupan di masa depan secara terorganisir ataupun tidak terorganisir.

\section{Pengalaman Kerja}

Menurut Hasibuan (2015), mengemukakan bahwa pengalaman kerja merupakan sebuah pekerjaan atau jabatan yang sudah dialami sebelumnya dalam jangka waktu tertentu, pengalaman kerja calon karyawan akan dijadikan pertimbangan dalam proses seleksi calon karyawan. Menurut Melayu S.P Hasibuan (2016), mengemukakan bahwa, seseorang dengan pengalaman adalah kandidat pegawai yang sudah siap akan bekerja. Pengalaman kerja calon karyawan tentu akan mendapat pertimbangan dalam proses seleksi calon pegawai. Pengalaman hanya bisa didapatkan melalui tempat kerja. Dapat disimpulkan bahwa pengalaman kerja yang cukup akan memudahkan karyawan dalam mengerjakan pekerjaannya. Menurut Marwansyah (2015), mengemukakan bahwa pengalaman kerja merupakan sebuah kemampuan dan keterampilan karyawan dalam mengemban tanggung jawab pada pekerjaannya.

\section{Kinerja Karyawan}

Menurut Kasmir (2016), menyatakan bahwa kinerja merupakan hasil kerja dan perilaku kerja yang diperoleh selama menyelesaikan pekerjaan yang diberikan dalam waktu yang ditetapkan. Menurut Makunegara (2017), mengemukakan kinerja merupakan hasil pekerjaan seseorang sebagai kualitas yang diperoleh karyawan selama menyelesaikan pekerjaannya serta tanggung jawab yang dibebankan oleh perusahaan. Menurut Amir dalam Lestari (2016) megemukakan kinerja yaitu sesuatu yang diperlihatkan oleh seseorang atau sebuah progress terkait dengan tugas kerja yang ditetapkan. Setelah tahap telaah pustaka, selanjutnya penulis 
akan memasuki tahap kerangka pemikiran teoritis. Dimana dalam kerangka pemikiran teoritis ini, penulis akan menjelaskan pengaruh variabel independen dengan variabel dependen secara parsial dan simultan berdasarkan teori yang terkait.

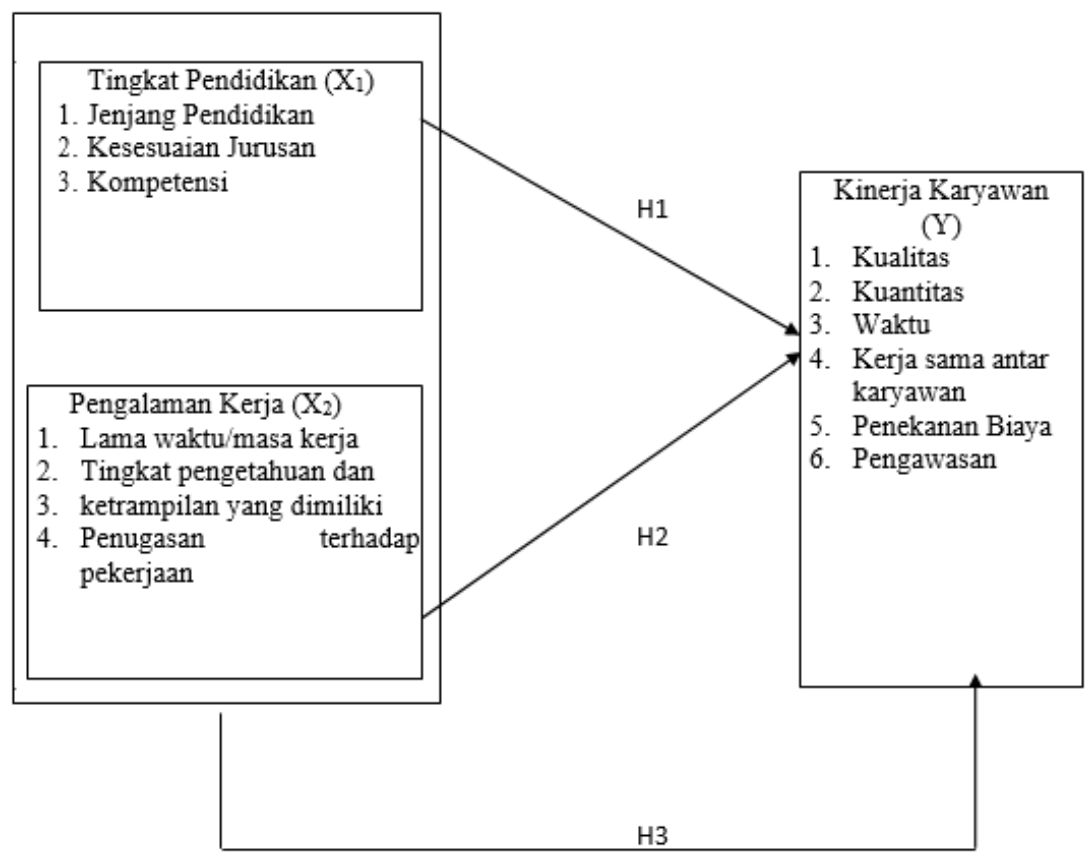

\section{Gambar 1 Kerangka Pemikiran Teoritis}

Keterangan:

$\mathrm{X} 1=$ Tingkat pendidikan

$\mathrm{X} 2 \quad=$ Pengalaman kerja

$\mathrm{Y} \quad=$ Kinerja karyawan

$\mathrm{H} 1=$ Pengaruh tingkat pendidikan pada kinerja karyawan

$\mathrm{H} 2=$ Pengaruh pengalaman kerja terhadap kinerja karyawan

H3 = Pengaruh tingkat pendidikan dan pengalaman kerja pada kinerja karyawan

Metode Penelitian

Menurut Arikunto (2013), mengemukakan bahwa metode penelitian adalah cara yang dipergunakan peneliti selama memperoleh data penelitian. Pada penelitian yang dilakukan oleh penulis, akan memakai metode kuantitatif dengan metode survey. Dalam penelitian ini penulis menggunakan sampel seluruh karyawan PT Jasamarga Tollroad Operator berjumlah 165 orang. Sesuai dengan perhitungan menggunakan rumus slovin, maka sampel yang akan diteliti oleh penulis dibulatkan menjadi 117 orang dari keseluruhan populasi.

Hasil dan Pembahasan Uji Validitas

Setiap variabel dibagi menjadi beberapa indikator, jika nilai $r$ hitung $>r$ tabel 0,1816 $(\mathrm{df}=117-2)$, maka dikatakan valid dan bisa di gunakan untuk analisis berikutnya.

Uji Reliabilitas

Penulis menguji data reliabilitas 117 responden dengan syarat jika nilai alpha $>0,60$ data dinyatakan reliabel. Hasil uji reliabilitas X1 sebesar 0,843 yang memiliki arti lebih besar dari 0,60, data X1 di nyatakan reliabel. Hasil uji reliabilitas X2 sebesar 0,874 yang memiliki arti lebih besar dari 0,60, data X2 di nyatakan reliabel. Hasil Y sebesar 0,841 yang memiliki arti lebih besar dari 0,60, data Y di nyatakan reliabel.

Uji Asumsi Klasik Uji Normalitas

Uji kenormalan data bisa digunakan dengan gambar Normal P-P Plot of Regression Standardized Residual. Uji normalitas bisa memakai uji statistik non-parametrik Kolmogorov-Smirnov (K-S) agar mengetahui signifikan data terdistribusi normal. 


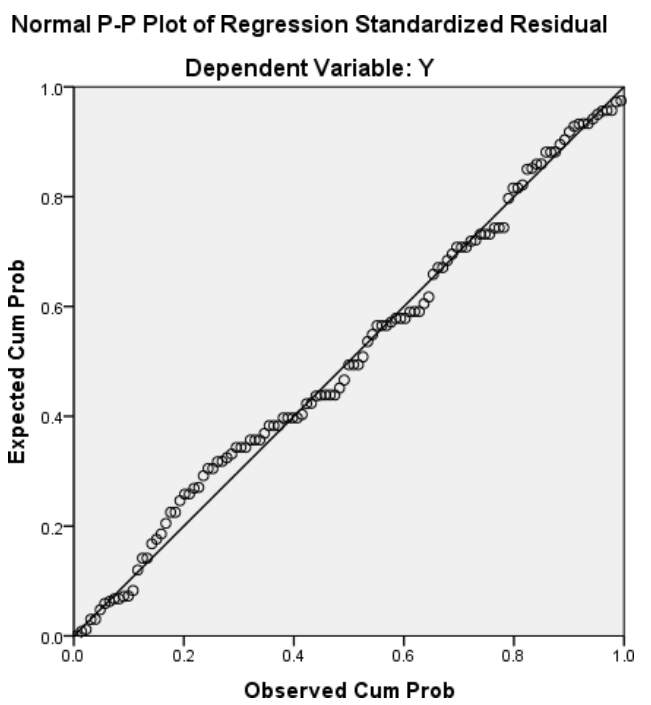

\section{Sumber: Output SPSS Statistics 22.0 Gambar 2 Hasil Uji Normalitas}

\section{Uji Multikolinearitas}

Hasil uji multikolinearitas, menujukkan nilai tolerance variabel Tingkat Pendidikan dan Pengalaman Kerja sebesar 0.741 dan memiliki kesimpulan bahwa variabel x1 dan x2 mempunyai nilai $>0,1$ dan sudah sesuai dengan dasar keputusan (nilai tolerance $>0,1$ ). Sedangkan nilai VIF sebesar 1.349 dan memiliki kesimpulan bahwa variabel x1 dan x2 mempunyai nilai $<10$ dan sudah sesuai dengan dasar keputusan (nilai VIF $<10$ ). Maka interpretasi dalam penelitian yaitu tidak adanya multikolinearitas antar variabel independen model regresi.

Uji Heteroskedastisitas

Dapat dilihat pada gambar, tidak ada heteroskedasitas, dimana peningkatan nilai variabel dependen sumbu $\mathrm{X}$ di ikuti peningkatan residual. Gambar hasil uji heteroskedastisitas, dibawah ini:

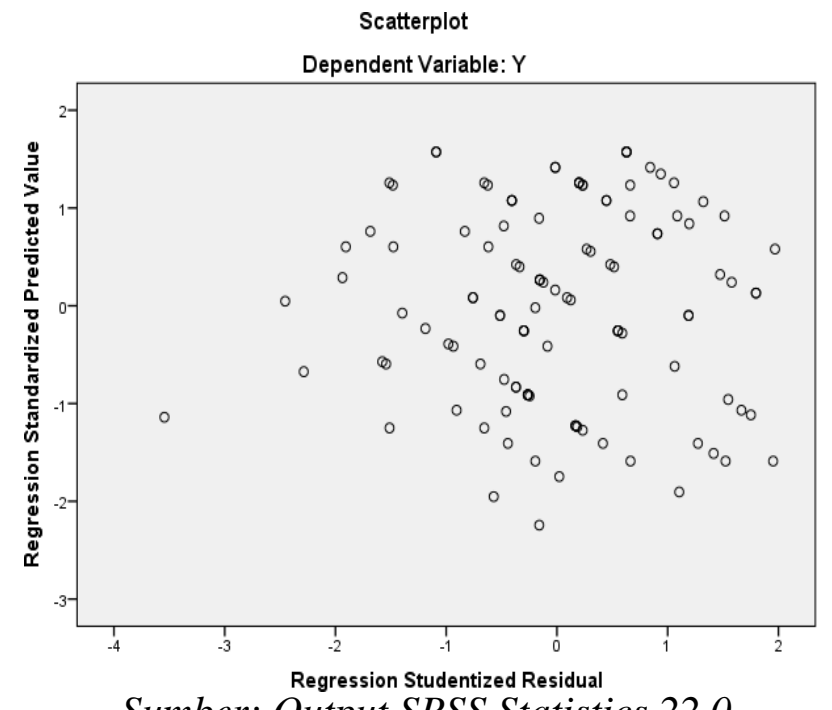

Sumber: Output SPSS Statistics 22.0

Gambar 3

Hasil Uji Heteroskedastisitas 


\section{Uji Autokorelasi}

Hasil uji autokorelasi, menyatakan nilai hitung durbin Watson sebesar 1,886. Sesuai taraf signifikansi 5\% $(0,05)$ dan sampel berjumlah $117(\mathrm{n}=117)$. Jumlah variabel independen 2 $(\mathrm{k}=2)$, maka nilai $\mathrm{dL}=1,663$ dan nilai $\mathrm{dU}=1,733$. Sesuai ketentuan $\mathrm{dU}<\mathrm{d}<4$-dU, maka disimpulkan 1,663 < 1,886 < 4-1,733=2,267 tidak terjadi autokorelasi.

\section{Analisis Korelasi Regresi Linear Berganda}

Persamaan regresi linier berganda dalam penelitian ini diuraikan dalam bentuk sebagai berikut :

$\mathrm{Y}=6.852+0.251 \mathrm{X}_{1}+0.541 \mathrm{X}_{2}$

1. Hasil uji koefisien regresi linier berganda menunjukkan nilai konstanta sebanyak 6.852 secara matematis mengatakan jika nilai variabel $\mathrm{X}_{1}$ (Tingkat Pendidikan) dan $\mathrm{X}_{2}$ $($ Pengalaman Kerja) $=0$ maka $Y$ (Kinerja Karyawan) yaitu 6.852. Dalam kata lain Kinerja Karyawan tanpa Tingkat Pendidikan dan Pengalaman Kerja adalah 6.852.

2. Koefisien regresi variabel $X_{1}$ (Tingkat Pendidikan) sebanyak 0.251 . Memiliki arti jika meningkat $\mathrm{X}_{1}$ (Tingkat Pendidikan) sebanyak satu skor sesuai asumsi variabel lain konstan mengakibatkann kenaikan Kinerja Karyawan sebanyak 0.251 pada konstanta 6.852 .

3. Koefisien regresi variabel $\mathrm{X}_{2}$ (Pengalaman Kerja) sebanyak 0.541. Memiliki arti jika meningkat $\mathrm{X}_{2}$ (Pengalaman Kerja) sebanyak satu skor sesuai asumsi variabel lain konstan mengakibatkan kenaikan Kinerja Karyawan sebanyak 0.541 pada konstanta 6.852 .

\section{Koefisien Korelasi Berganda}

Pada hasil koefisien korelasi berganda, menunjukkan Model Summary koefisien korelasi berganda variabel Tingkat Pendidikan dan Pengalaman Kerja pada Kinerja Karyawan (R) adalah 0.806, maka variabel $\mathrm{x} 1$ dan $\mathrm{x} 2$ yaitu Tingkat Pendidikan dan Pengalaman Kerja mempunyai tingkat hubungan positif sangat kuat interval (0.80-1.000) terhadap Kinerja Karyawan.

\section{Uji Koefisen Determinasi $\left(\mathbf{R}^{2}\right)$}

Pada hasil uji koefisien determinasi $\left(\mathrm{R}_{2}\right)$ menunjukkan nilai adjusted $R$ square menunjukkan besar nya pengaruh variabel independen pada variabel dependen bisa di jelaskan pada model persamaan 0.643 dengan tingkat persentase sebesar $64.3 \%$. Uji ini menunjukan besarnya kontribusi pengaruh variabel Tingkat Pendidikan $\left(\mathrm{X}_{1}\right)$ dan Pengalaman Kerja $\left(\mathrm{X}_{2}\right)$ pada Kinerja Karyawan (Y) bisa di jelaskan model persamaan 64,3\% dan sisa nya sebesar $100 \%$ - $64.3 \%=35.7 \%$ di pengaruhi faktor-faktor lain, seperti: pelatihan, insentif, yang tidak di masukkan pada model.

\section{Uji Hipotesis Uji t}

\section{Tabel 1}

\section{Hasil Uji Statistik t (Parsial)}

Coefficients

\begin{tabular}{|c|c|c|c|c|c|c|c|c|}
\hline & \multirow[b]{2}{*}{ Model } & \multicolumn{2}{|c|}{$\begin{array}{c}\text { Unstandardized } \\
\text { Coefficients }\end{array}$} & \multirow{2}{*}{$\begin{array}{c}\begin{array}{c}\text { Standardized } \\
\text { Coefficients }\end{array} \\
\text { Beta } \\
\end{array}$} & \multirow[b]{2}{*}{$\mathrm{T}$} & \multirow[b]{2}{*}{ Sig. } & \multicolumn{2}{|c|}{$\begin{array}{c}\text { Collinearity } \\
\text { Statistics }\end{array}$} \\
\hline & & B & Std. Error & & & & Tolerance & VIF \\
\hline 1 & (Constant) & 6.852 & 1.973 & & 3.473 & .001 & & \\
\hline & $\mathrm{X} 1$ & 251 & .062 & .263 & 4.075 & .000 & .741 & 1.349 \\
\hline & $\mathrm{X} 2$ & .541 & .054 & .640 & 9.924 & .000 & .741 & 1.349 \\
\hline
\end{tabular}

a. Dependent Variable: Y

Sumber: Output SPSS Statistics 22.0

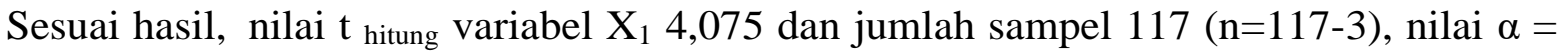
0.05 di peroleh nilai $t_{\text {tabel }}$ ( ) 1.658. Disimpulkan bahwa $t_{\text {hitung }}(4,075)>$ nilai $t_{\text {tabel }}$ $(1,658)$. 
Dari hasil, ditarik kesimpulan $\mathrm{H}_{0}$ di tolak dan $\mathrm{H}_{1}$ di terima dengan keputusan ada pengaruh positif signifikan antar tingkat pendidikan dengan kinerja.

Untuk nilai t hitung variabel $X_{2}$, diperoleh nilai sebesar 9,924 dengan sampel $117(n=117-3)$,

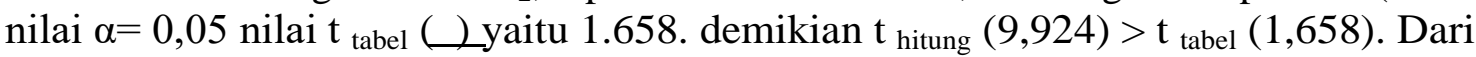
hasil, ditarik kesimpulan $\mathrm{H}_{0}$ di tolak dan $\mathrm{H}_{2}$ di terima dengan keputusan terdapat pengaruh positif signifikan pengalaman kerja dengan kinerja.

Uji F

\section{Tabel 2}

\section{Hasil Uji Statistik F (Simultan)}

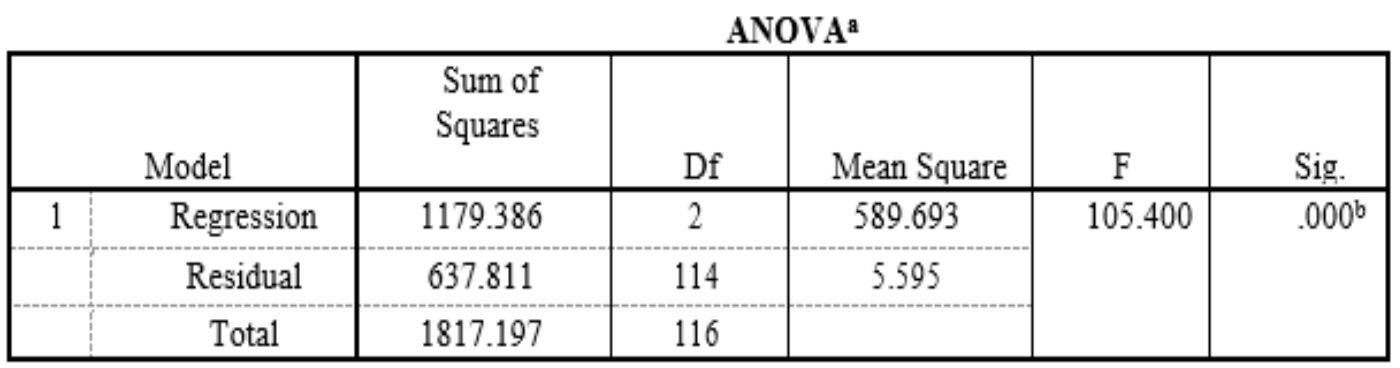

a. Dependent Variable: Y

b. Predictors: (Constant), X2, X1

Sumber: Output SPSS Statistics 22.0

Sesuai hasil, bahwa variabel Tingkat Pendidikan $\left(\mathrm{X}_{1}\right)$, Pengalaman Kerja $\left(\mathrm{X}_{2}\right)$, dan Kinerja Karyawan (Y) mempunyai nilai $F_{\text {hitung }} 105.400>$ F 0.05 (2:114) = Tabel f 3.08 (df = n-k-1) atau $(114=117-2-1)$. Hasil nilai sign $0,000<0,05$ dan nilai sign $0.000<0.05$. Artinya Tingkat Pendidikan $\left(\mathrm{X}_{1}\right)$ dan Pengalaman Kerja $\left(\mathrm{X}_{2}\right)$ secara simultan memiliki pengaruh positif pada Kinerja Karyawan (Y), maka $\mathrm{H}_{3}$ diterima.

\section{KESIMPULAN}

1. Hasil uji koefisien korelasi berganda ditarik kesimpulan kedua variabel independen Tingkat Pendidikan $\left(\mathrm{X}_{1}\right)$ dan Pengalaman Kerja $\left(\mathrm{X}_{2}\right)$ terrdapat hubungan positif sangat kuat di interval $(0,80-1,000)$ pada variabel dependen Kinerja Karyawan(Y).

2. Hasil uji koefisien determinasi $\left(\mathrm{R}^{2}\right)$ ditarik kesimpulan besarnya kontribusi pengaruh variabel Tingkat Pendidikan $\left(\mathrm{X}_{1}\right)$ dan Pengalaman Kerja $\left(\mathrm{X}_{2}\right)$ pada Kinerja Karyawan (Y) sebesar $64,3 \%$. Dan sisa nya 35,7 \% di pengaruhi faktor-faktor lain: pelatihan, insentif, lingkungan kerja, dan sebagainya yang tidak dimasukkan dalam model penelitian.

3. Hasil uji signifikansi parameter individual (Uji T) ditarik kesimpulan $\mathrm{H}_{0}$ ditolak dan $\mathrm{H}_{1}$ diterima maka ada pengaruh positif tingkat pendidikan pada Kinerja Karyawan secara parsial. Serta $\mathrm{H}_{0}$ di tolak dan $\mathrm{H}_{2}$ di terima maka terrdapat pengaruh positif Pengalaman Kerja pada Kinerja Karyawan secara parsial.

4. Uji serentak (Uji F) ditarik kesimpulan Tingkat Pendidikan dan Pengalaman Kerja ada pengaruh positif pada Kinerja Karyawan secara simultan.

\section{SARAN}

1. Karyawan PT Jasamarga Tollroad Operator sering tidak menyelesaikan pekerjaannya dengan tepat waktu. Masih banyak beberapa karyawan yang menyelesaikan tugasnya melewati batas waktu yang ditentukan, karena ada beberapa pekerjaan yang masih kurang dipahami. Dengan demikian penulis memberikan saran, perusahaan harus memberikan pemahaman lebih tentang pekerjaan karyawan di bidang nya masing- masing, agar karyawan lebih mudah memahami pekerjaanya sehingga dapat menyelesaikan lebih cepat. 
2. Beberapa karyawan di PT Jasamarga Tollroad Operator tidak mampu menguasai peralatan kerja yang ada. Oleh sebab itu penulis memberikan saran, Perusahaan diharapkan dapat memberikan bimbingan, masukan, dan pemahaman kepada karyawan yang belum cukup memiliki pengalaman kerja. Agar dapat lebih mudah memahami peralatan kerja yang ada di perusahaan.

3. Karyawan di PT Jasamarga Tollroad Operator merasa kualitas kerja nya tidak lebih baik dibandingkan dengan rekan kerja nya yang lain. Perusahaan diharapkan dapat lebih meningkatkan kualitas kerja bagi pegawainya dengan memberikan beberapa pemahaman terkait dengan pekerjaannya atau dapat memberikan pengalaman kerja di dalam perusahaan agar kinerja mereka semakin meningkat.

\section{DAFTAR PUSATAKA}

Bangun, Wilson. (2012). Manajemen Sumber Daya Manusia. Erlangga. Jakarta

Bintoro, M.T \& Daryanto. (2017) .Manajemen Penilaian Kinerja Karyawan. Gava Media, Daerah Istimewa Yogyakarta (DIY)

Dawi Priyatno. (2010). Paham Analisis Statistik Data dengan SPSS. Mediakom, Yogyakarta Dessler, G. (2000). Manajemen Sumber Daya Manusia. PT. Indeks Gramedia, Jakarta.

Foster, Bill. (2001). Pembinaan Untuk Peningkatan Sumber Daya Manusia. PPM, Jakarta. Hariandja, Marihot T. E. (2002). Manajemen Sumber Daya Manusia. Grasindo, Jakarta.

Hasbullah. (2001). Dasar-Dasar Ilmu Pendidikan. PT. Rajagravindo Persada, Jakarta. 